\section{Propranolol-induced Depression}

SIR,-Therapeutic indications for the betareceptor adrenergic blocking agent propranolol, of which we have experience, include angina, cardiac arrythmias, and hypertension ${ }^{1}$; and there are reports of its value in phaeochromocytoma not amenable to surgery, ${ }^{2}$ hypertrophic obstructive cardiomyopathy, ${ }^{3}$ even Parkinsonian tremor, anxiety, ${ }^{5}$ the sympathetic side-effects of thyrotoxicosis, ${ }^{\circ}$ and cyanotic attacks in Fallot's tetralogy. ${ }^{7}$ It is likely, therefore, that many patients will receive propranolol on a long-term basis. For this reason I would like to report the relatively high incidence of depression observed in a series of 89 hypertensive patients who received propranolol for cardiac arrhythmias.

I was alerted to the possibility of propranolol-induced depression by the fact that two of three suicides over a two-year period among the 750 patients attending the Dunedin hypertensive clinic were on drug regimen including propranolol. The 89 patients who had received propranolol for periods varying from two weeks to more than two years had been interviewed regularly-at first fortnightly, then monthly, when they attended for a day test, during which five to seven standing and lying blood-pressure readings were recorded. The notes made at these visits were scrutinized for depressive symptoms volunteered by the patients.

The depressive symptoms were graded as follows: Grade I-irritability, insomnia, nightmares, lack of drive and energy withou observed hypotension; Grade II-depression; Grade III-depression necessitating the administration of antidepressants ; Grade IV-suicide. Of the 89 patients 20 volunteered or exhibited depression as follows:

\begin{tabular}{c|c|c|c}
\hline Grade I & Grade II & Grade III & Grade IV \\
\hline 8 & 8 & 2 & 2 \\
\hline
\end{tabular}

Of the 69 patients who did not volunteer depression it was possible to interrogate 47, while they were taking propranolol, about their mental state. Of the 47 patients a further 7 admitted to Grade I and one to Grade III depression. Ten of the 11 patients experiencing Grade II and Grade III depression lost this when propranolol was stopped. The eleventh patient has only recently stopped propranolol.

When the 89 patients were grouped in three categories according to the duration of propranolol administration it was found that the longer the duration of propranolol therapy the higher the incidence of depression.

\begin{tabular}{c|c|c|c} 
& \multicolumn{3}{|c}{$\begin{array}{c}\text { Duration of Propranolol } \\
\text { Administration }\end{array}$} \\
\cline { 2 - 4 } & $\begin{array}{c}\text { Less than } \\
\text { 2 Weeks }\end{array}$ & $\begin{array}{c}2 \\
\text { 3 Weeks- } \\
\text { 3 Munths }\end{array}$ & $\begin{array}{c}\text { More than } \\
\text { 3 Months }\end{array}$ \\
\hline $\begin{array}{c}\text { No. treated } \\
\text { No. } \\
\text { with depres- } \\
\text { sive symptoms }\end{array}$ & 22 & 24 & 43 \\
\hline & 2 & 5 & 21 \\
\hline
\end{tabular}

When the 89 patients were grouped in three categories according to daily dosage of propranolol received it was found that there was an increase in the incidence of depression among the patients on the higher dose.
Among the 89 propranolol-treated patients there were long-standing hypertensives who had been treated with reserpine in the 1950's. In fact 23 of the 89 propranolol-treated patients had had, or were having, reserpine. In 13 of these reserpine had been stopped because of reserpine-induced depression. Of the 13 patients who had had reserpine depression 11 developed depression when propranolol was administered subsequently, and two who received a daily dose of less than $9 \mathrm{mg}$. of propranolo for under three months did not develop dipression. In these two patients reserpine depression had been manifest after 6 and 11 years of continuous reserpine administration. Ten of the 23 patients who had had reserpine experienced no reserpine depression, and four were still taking reserpine as part of their hypntensive regimen. None of these 10 patients experienced depression when taking propranolol.

Two patients were started on reserpine and propranolol simultaneously; both experienced depressive symptoms, which persisted when reserpine was stopped.

\begin{tabular}{|c|c|c|c|}
\hline & \multicolumn{3}{|c|}{ Daily Propranolol Dose } \\
\hline & $\begin{array}{l}\text { Less than } \\
45 \mathrm{mg} .\end{array}$ & $120 \mathrm{mg}$. & $\begin{array}{l}\text { More than } \\
120 \mathrm{mg} .\end{array}$ \\
\hline \multirow{3}{*}{$\begin{array}{l}\text { No. treated } \\
\text { No. with depres- } \\
\text { sive symptoms }\end{array}$} & 44 & 39 & 6 \\
\hline & 10 & 13 & 3 \\
\hline & $23 \%$ & $33 \%$ & $50 \%$ \\
\hline
\end{tabular}

A few of the patients who experienced depression while taking reserpine or while taking propranolol also experienced depression while taking methyldopa or guanethidine. It is possible that hypertensive patients because of some biochemical abnormality related to either hypertension or to hypotensive therapy, or because of acceleration of atherosclerosis, are more vulnerable to depression. However, alertness to possible drug induced depression from propranolol during long-term and especially high dosage (daily dose more than $120 \mathrm{mg}$.) regimens would appear to be indicated.

Wellcome Medical Research Institute,

H. J. WAAL.

University of Otago Medical School,

Dunedin, New Zealand.

\section{REFERENCES}

Waal, H. J., Clin. Pharmacol. Ther., 1966, 7 , 588. Cardiol. ' 18 394.' Cherian. G.. Brockington. I. F., Shah, P. M.
Oakley, C. M., and Goodwin, J. F., Brit. med. Oakley, C. M. 7., 1966, 1. 895.
Owen. D. A L., and Marsden, C. D., Lancet,
1965. 2. 1259.

Granville-Grossman, K. L., and Turner, P., Howitt. G., and Rowlands, D. J., ibid., 1966 1, 628 . P and Gotsman, M. S., Brit. Heart Singh. $1966, \quad 28,98$.

\section{Metallic Mercury Poisoning}

SIR,-Many doctors seem quite unaware of the toxicity of metallic mercury and of the ease with which this metal can be absorbed by inhalation, ingestion, or skin contact.

In one of the fascinating articles on mercurialism (11 February, pp. 340, 342, and $347)$ Dr. H. R. M. Johnson and Dr. O. Koumides suggest that "the long-held belief that metallic mercury is non-toxic when introduced into the human body is untrue." It is indeed. Fortunately the dangers are recognized in industries using mercury and by the factory inspectorate of the Ministry of Labour. As an engineer familiar with the problems, and a doctor previously somewhat ignorant of them, we should like to draw attention to the risk of even slight exposure to metallic mercury.

The saturated vapour pressure of mercury at room temperature corresponds to $20 \mathrm{mg}$. per cubic metre, while recommended safety levels for mercury vapour are $0.1 \mathrm{mg} . / \mathrm{M}^{3}$ in the U.S.A. and U.K., and $0.001 \mathrm{mg} . / \mathrm{M}^{3}$ in Germany. The higher figure may be too permissive. ${ }^{1}$ Measurements of the actual concentrations of mercury vapour reached in an ordinary room have shown a level of 0.3 mg. $/ \mathrm{M}^{3}$ at a point 20 feet from a $200 \mathrm{ml}$. spillage of mercury. ${ }^{2}$

After spillage of several much smaller amounts totalling only a few millilitres on to a bench and composition floor the concentration of mercury vapour in the air rose to the U.S. safety level, and that in the exhaust of the laboratory vacuum cleaner exceeded this limit by 25 to 30 times. Without special decontamination procedures raised mercury vapour levels can persist for many months or even years. Agitation and particulation increase air concentrations, so that ordinary cleaning is likely to make matters worse. It would be interesting to measure mercury vapour concentrations in school physics laboratories and in wards where mercury from thermometers and sphygmomanometers has been spilled. The risks are appreciable. Fraser ${ }^{3}$ found that dogs exposed to mercury vapour at concentrations above $3.05 \mathrm{mg} . / \mathrm{M}^{3}$ developed marked signs of mercury poisoning.

Anyone interested in the subject can find details in books on toxicology, ${ }^{4-6}$ but it may be mentioned here that felt workers' erethism, with its neurological and mental changes, and glassblowers' shakes are no more than examples of C.N.S. damage due to mercury poisoning. The eyes, ears, teeth, gums, kidneys, circulation, mucous membranes, and other tissues can also be affected. Although workers in the felt-hat trade used mercuric nitrate, they appear to have suffered from the effects of inhaling and absorbing metallic mercury released in the course of their work. The Mad Hatter was no mere figment of Lewis Carroll's fertile imagination.

Excretion of mercury via the fingertips, described in the paper by Mr. H. B. Devlin and Dr. M. Sudlow (11 February, p. 347), appears to confirm the "folklore" of glassblowers employed in making scientific instruments. The brass tools of workers poisoned with mercury apparently became plated by shining metallic mercury from repeated contact with the fingertips.

Poisoning with metallic mercury is a real risk, which can be avoided if the dangers are widely known and preventive measures taken. It seems at least possible that some undiagnosed conditions are due to unrecognized mercury poisoning.-We are, etc.,

$$
\text { G. F. B. BirdwOOD. }
$$

King's Langley,

A. I. RAY

Herts.

REFERENCES

Patty, F. A. (ed.), Industrial Hygiene and Toxicology, 1962. vol. 2 , 2nd ed. New York.

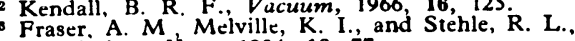
Fraser. A. M M Melving $1934,16,77$.

7. indust. Hyg., 1934, 16, 77. Materials, 1957. New York.

Drowning E., Toxicity of Industrial Metals, 1961. l.ondon. worth Health in Mercurial Poisoning-Preventive Measures in
Handling Liquid Mercury and the Removal of Contamination. 1966. Ministry of Labour. H.M Factory Inspectorate leafet No. F.337. London. 